\title{
Guerbet Reaction of Primary Alcohols Leading to $\beta$-Alkylated Dimer Alcohols Catalyzed by Iridium Complexes
}

Toyomi Matsu-ura, Satoshi Sakaguchi, and Yasutaka Ishii*

Department of Applied Chemistry \& High Technology Research Center, Faculty of Engineering, Kansai University, Suita, Osaka 564-8680, Japan

ishii@ipcku.kansai-u.ac.jp

Supporting Information

Table of contents

S2 Copies of ${ }^{1} \mathrm{H}$ and ${ }^{13} \mathrm{C}$ NMR spectra for $\mathbf{2 b}$

S3 Copies of ${ }^{1} \mathrm{H}$ and ${ }^{13} \mathrm{C}$ NMR spectra for $\mathbf{2 c}$

S4 Copies of ${ }^{1} \mathrm{H}$ and ${ }^{13} \mathrm{C}$ NMR spectra for $\mathbf{2 d}$

S5 Copies of ${ }^{1} \mathrm{H}$ and ${ }^{13} \mathrm{C}$ NMR spectra for $\mathbf{2 e}$

S6 Copies of ${ }^{1} \mathrm{H}$ and ${ }^{13} \mathrm{C}$ NMR spectra for $\mathbf{2 f}$

S7 Copies of ${ }^{1} \mathrm{H}$ and ${ }^{13} \mathrm{C}$ NMR spectra for $\mathbf{2 g}$

S8 Copies of ${ }^{1} \mathrm{H}$ and ${ }^{13} \mathrm{C}$ NMR spectra for $\mathbf{2 h}$ 

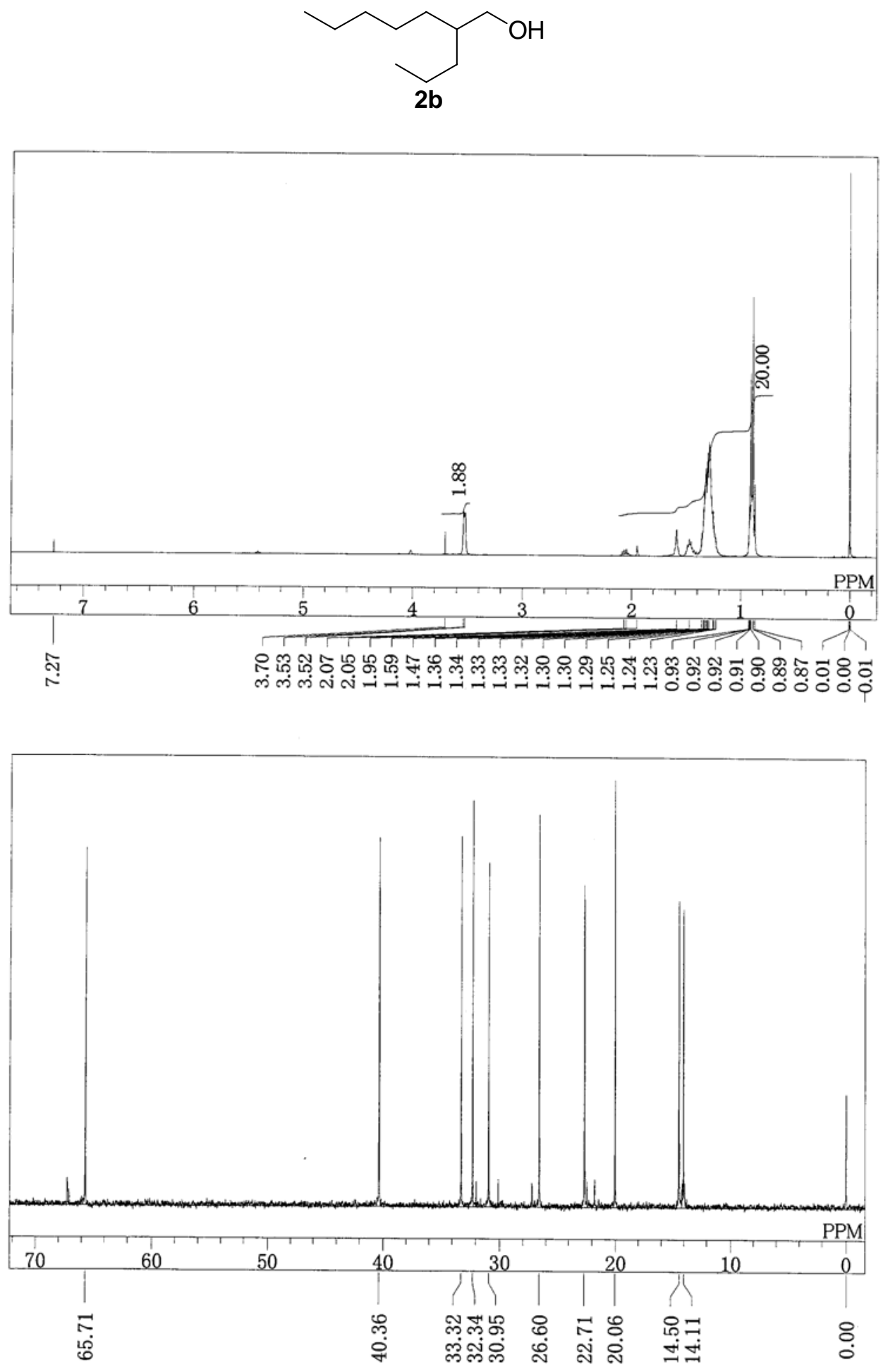

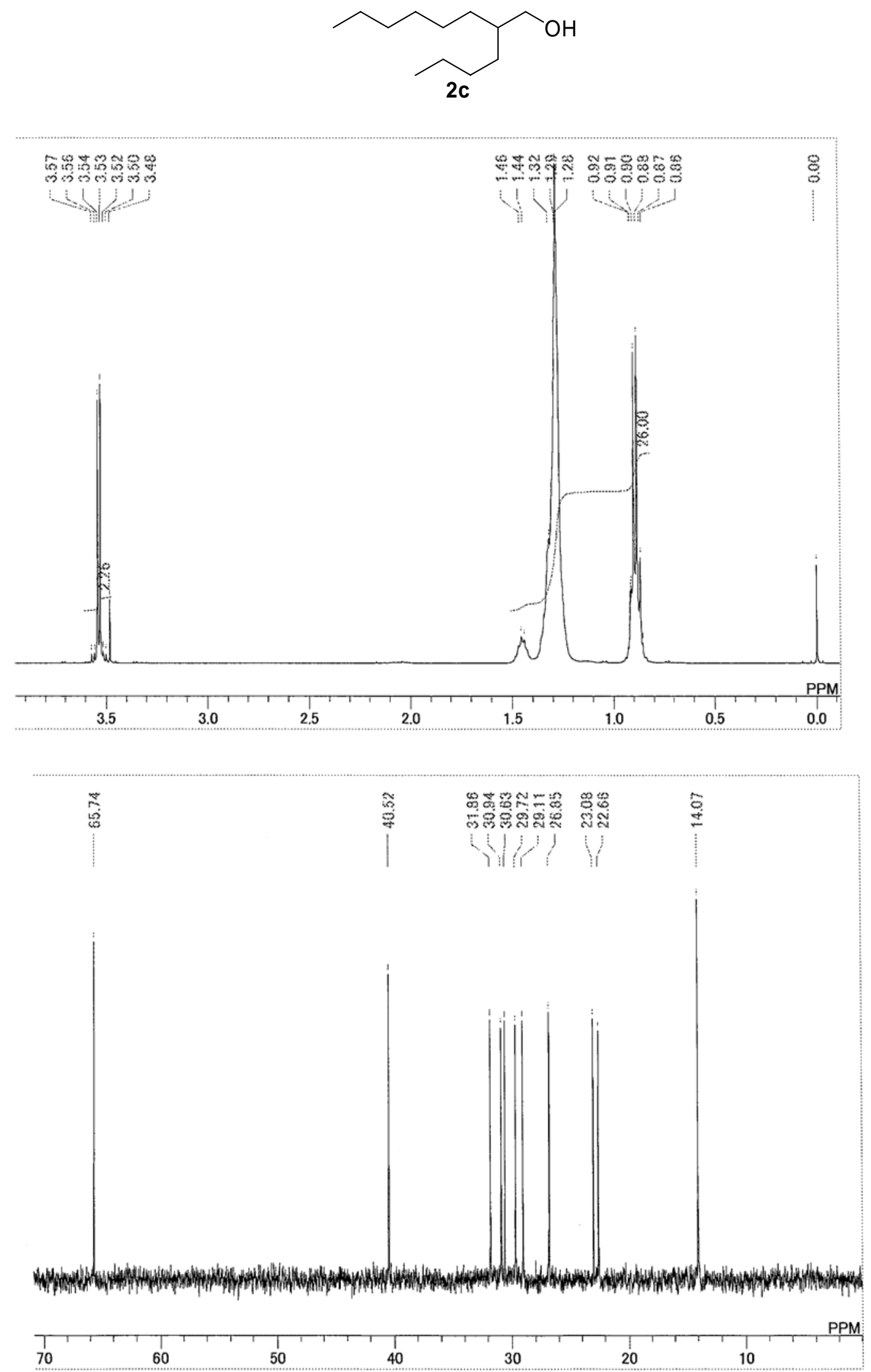

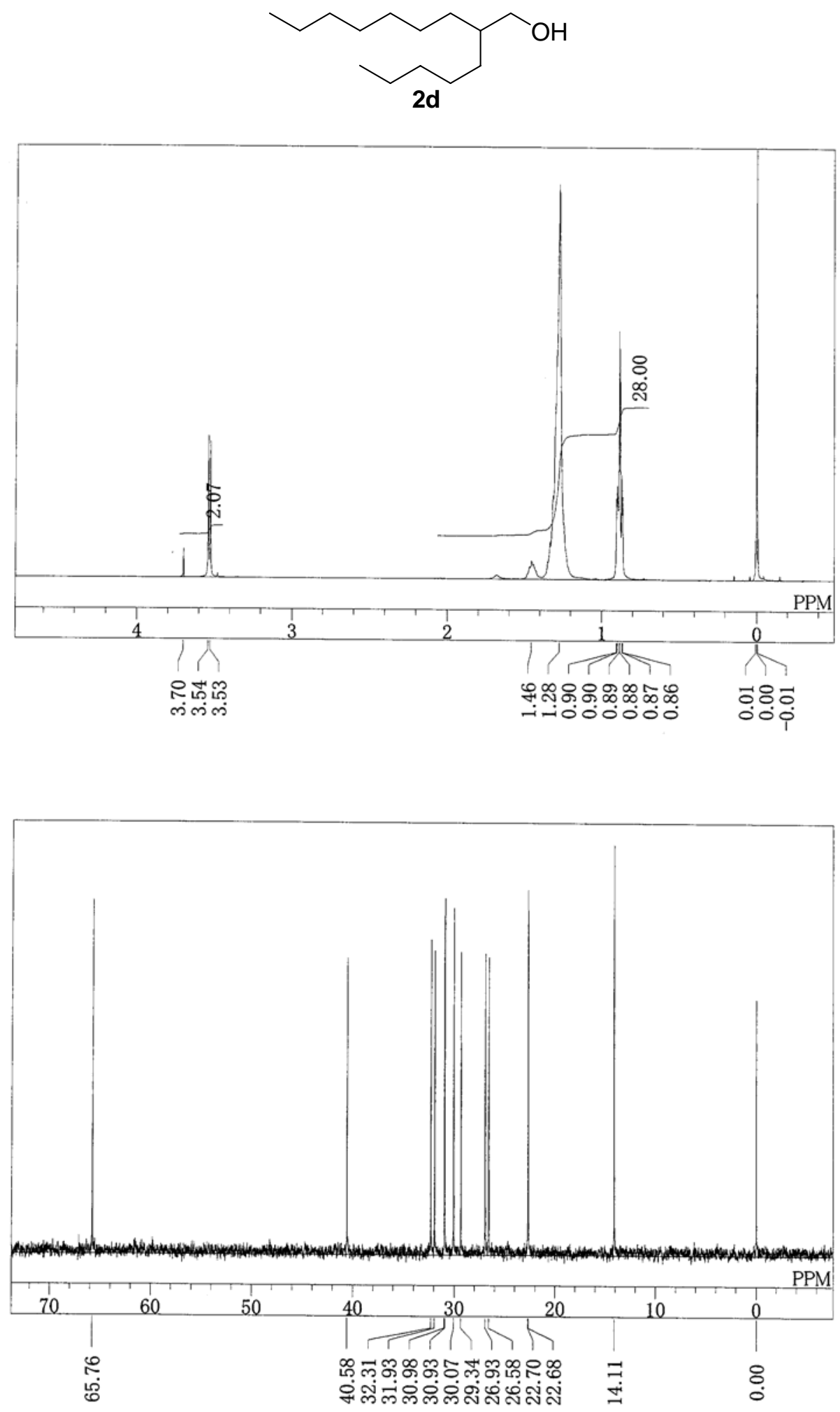

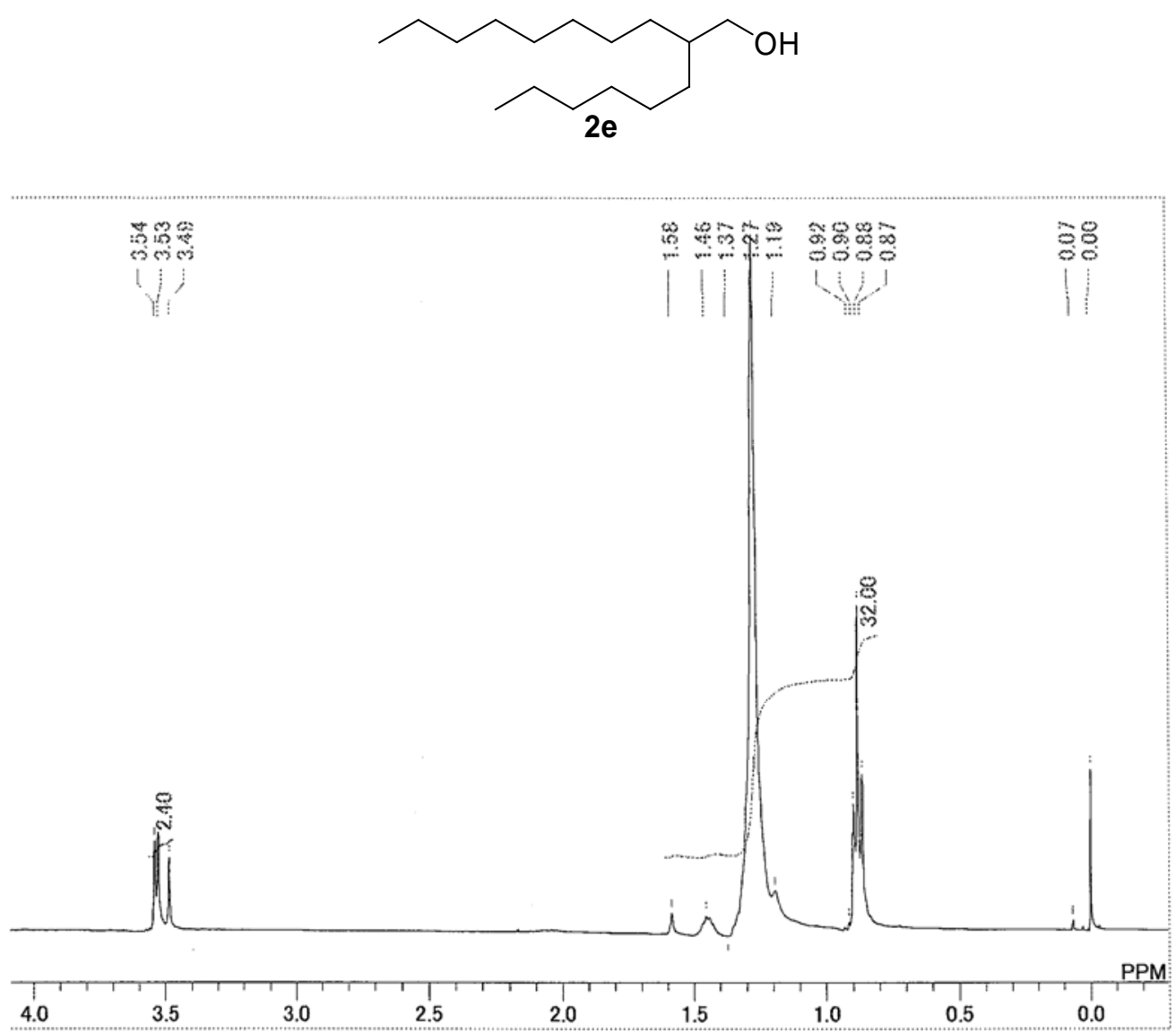

$2006.5 .24 \mathrm{CB} \cdot 0 \mathrm{H} 13 \mathrm{C}$

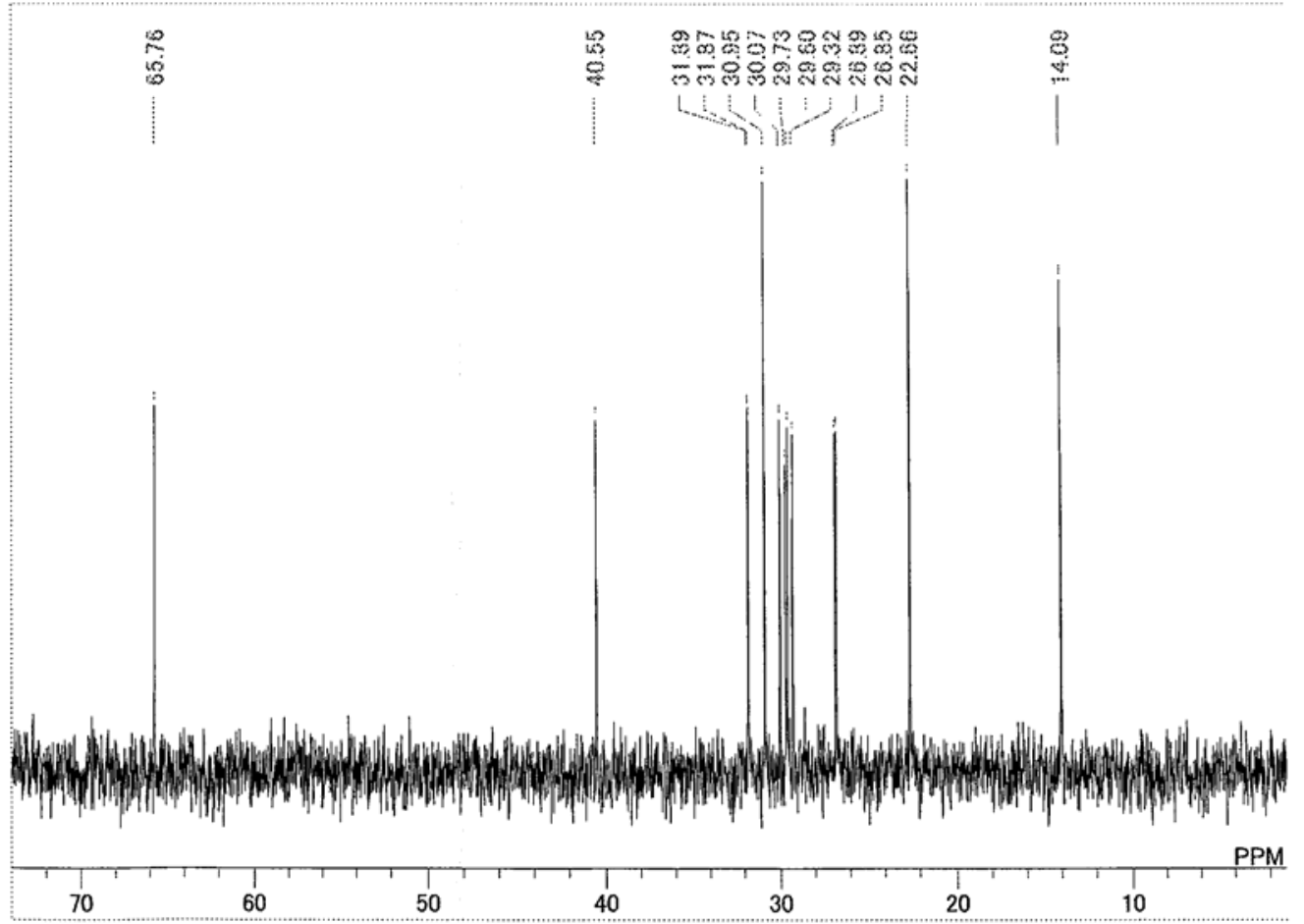



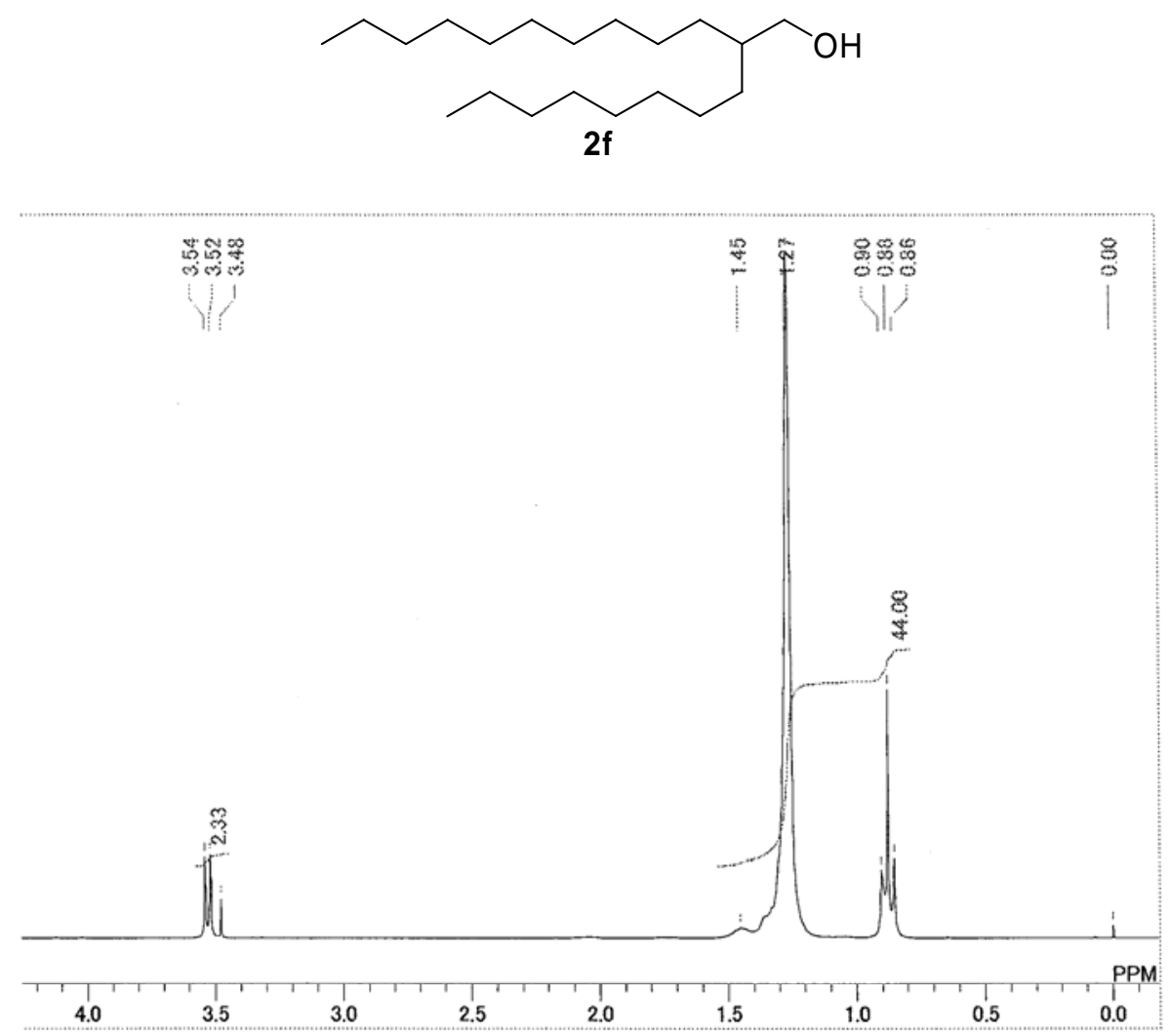

$2006.5 .23 \mathrm{C10}-\mathrm{OH} 13 \mathrm{C}$

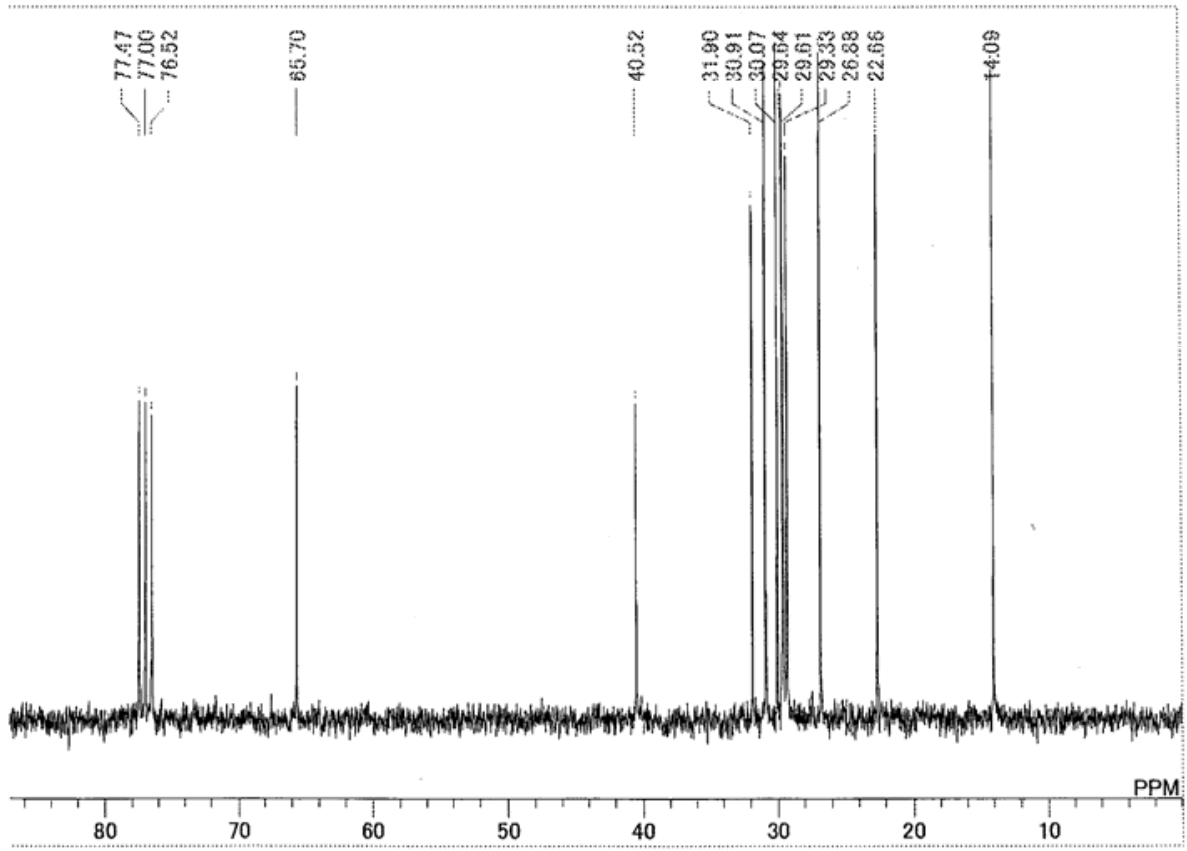



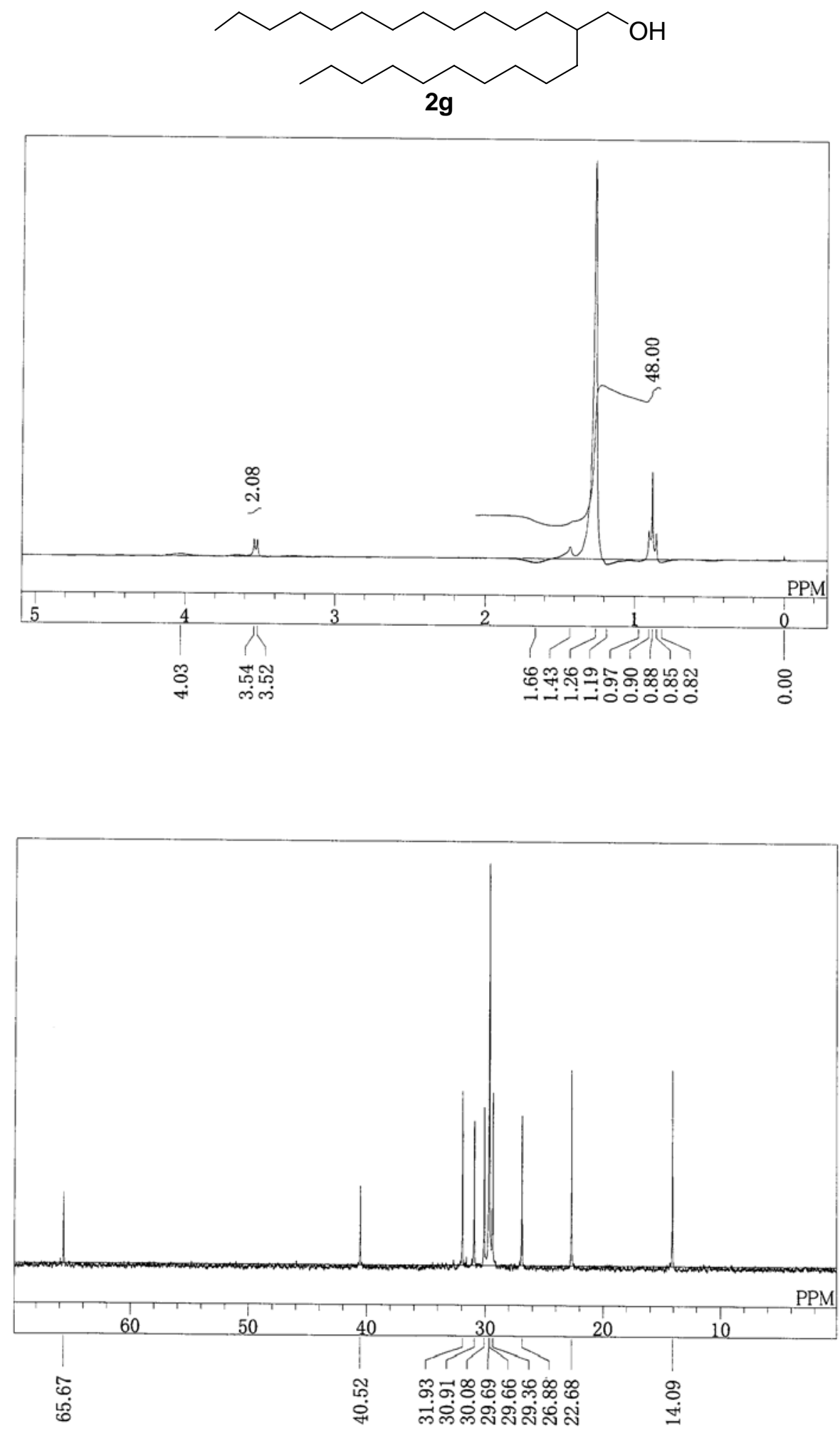

- S7 - 


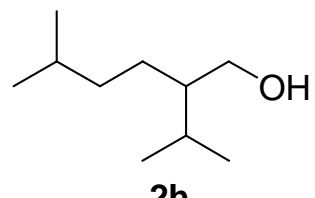

$2 \mathrm{~h}$
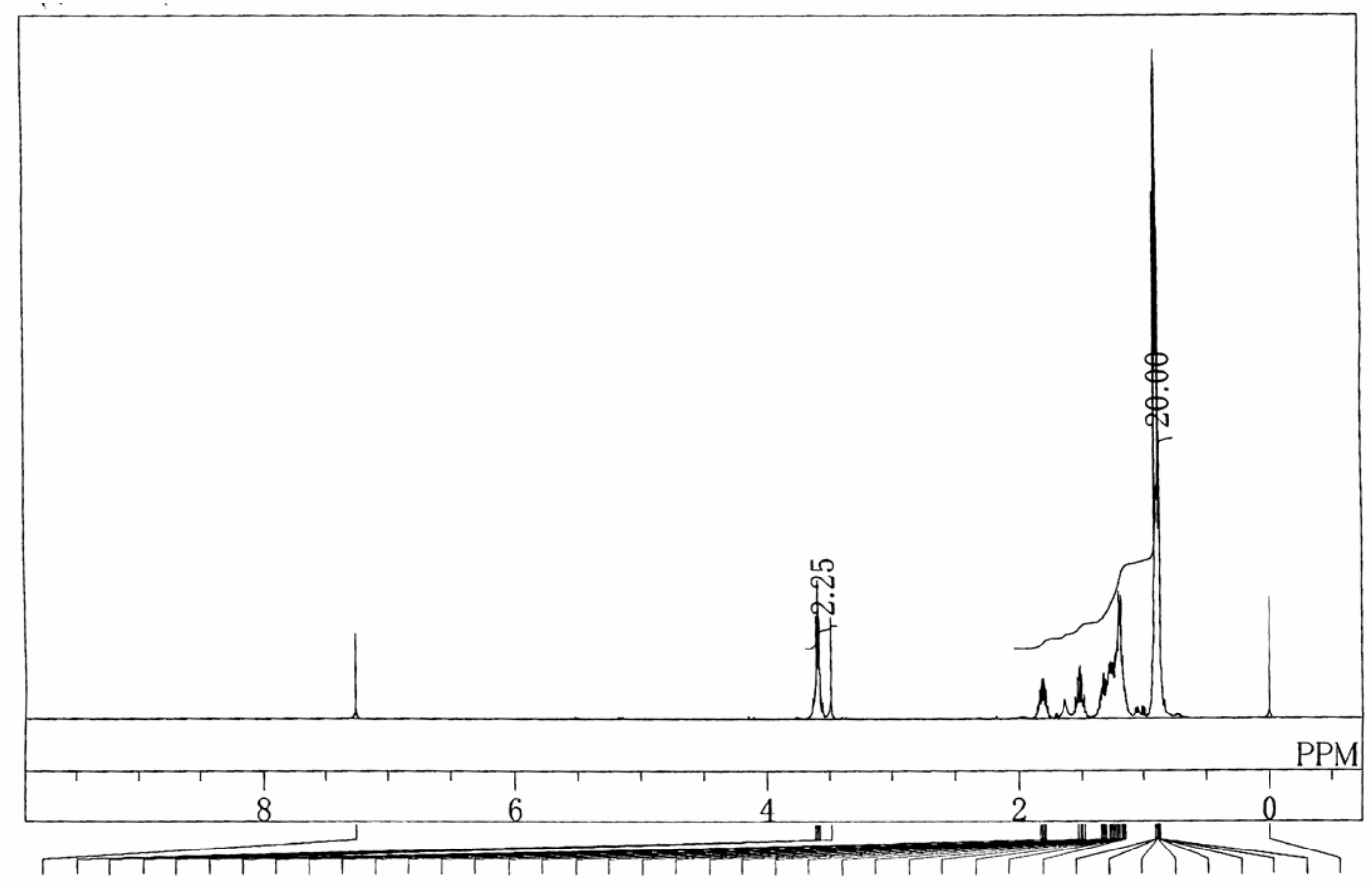

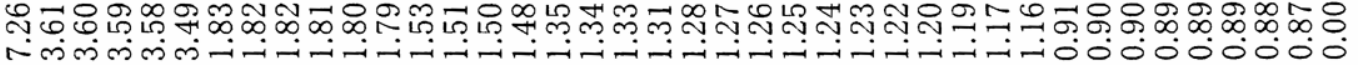

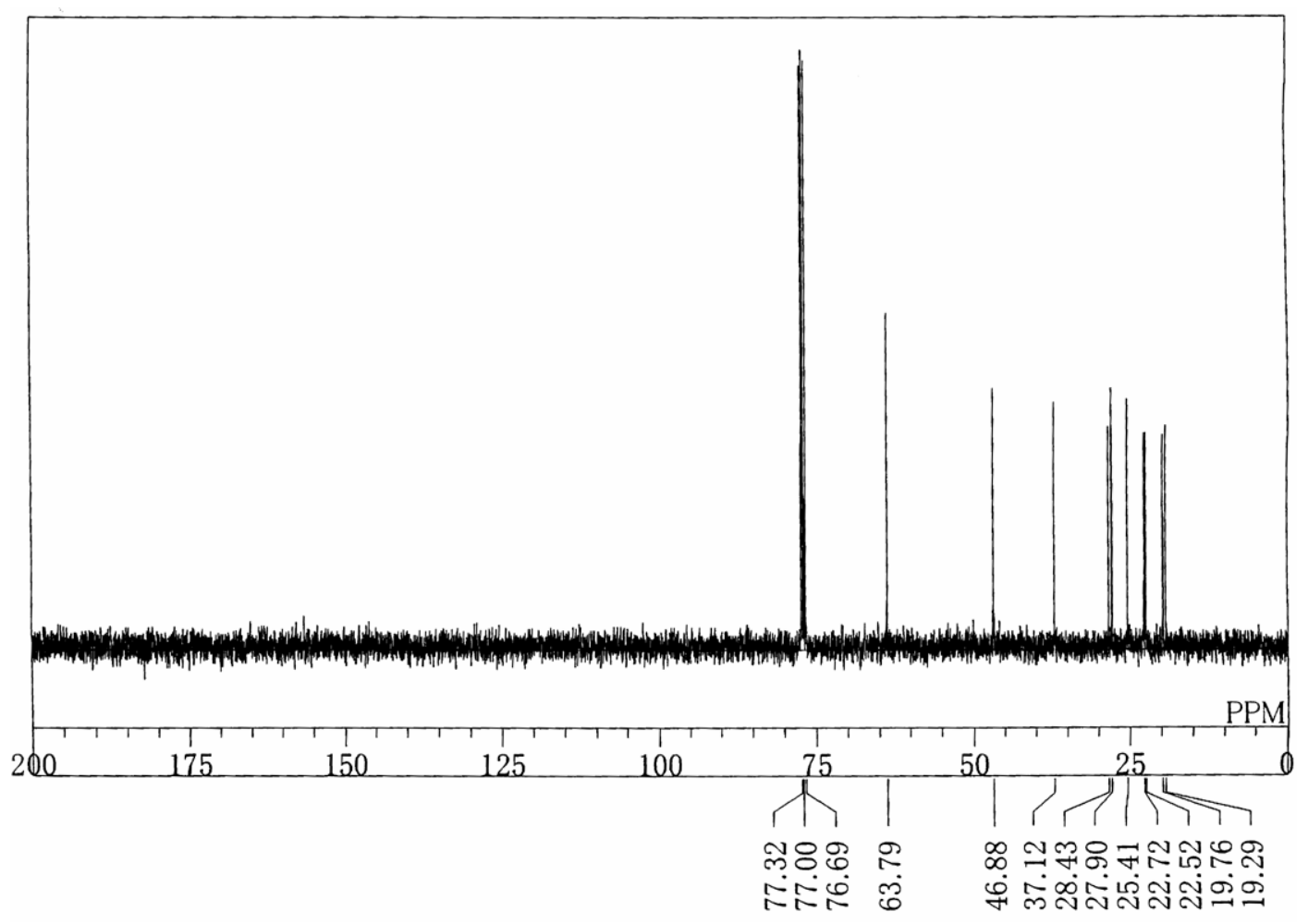

